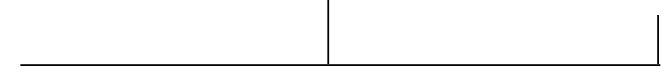

Rev. Latinoam. Psicopat. Fund., São Paulo, v. 11, n. 1, p. 55-68, março 2008

\title{
Sobre os princípios da psicopatologia psicanalítica: sexuação e invenção
}

\author{
Tânia Coelho dos Santos
}

Acredito que essa pesquisa sobre os fundamentos da psicopatologia psicanalítica contribua para atualizar os princípios da direção da cura psicanalítica, retomando-os a partir dos impasses da sexuação. Isso é importante para orientar os praticantes da psicanálise aplicada sobre o que podemos esperar - sem abrir mão dos princípios dessa prática no âmbito dos efeitos terapêuticos. Acredito que essa discussão contribua para renovar a controvérsia sobre a diferença estrutural entre a neurose e a psicose na contemporaneidade.

Palavras-chave: Psicopatologia psicanalítica, pulsão, sexuação, invenção 
A pesquisa em psicanálise não se reduz à repetição dos clássicos, ao contrário do que muitos críticos de nosso método de trabalho costumam afirmar. Ela nos exige atualizar as ferramentas teóricas e a experiência clínica para enfrentar os efeitos do progresso das ciências: as novas configurações do mal-estar e do sofrimento psíquico na civilização. Para a atualização do nosso conhecimento, é preciso incorporar urgentemente as transformações epistemológicas do discurso da ciência. Parece um paradoxo, mas o sujeito sobre o qual a psicanálise opera é o sujeito da ciência, logo, essas mudanças têm efeitos muito importantes nas relações da pulsão com o Outro. Em particular, aquelas que são efeito da própria difusão do discurso analítico e da radicalização das ideologias individualistas, na medida em que contribuem para a absolutização do direito ao gozo, empobrecendo as obrigações que sedimentam os laços sociais. Elas se refletem nos impasses novos que o sujeito encontra para tomar seu lugar no campo da fala, pois são a conseqüência dos novos imperativos ordenadores da cultura, imperativos estes que impulsionam ao consumo, aos excessos e às satisfações excluídas do circuito da fala.

Novas modalidades de sintoma, com efeitos inusitados sobre o laço social, desafiam o ato analítico, requerendo a renovação do campo da interpretação e da formação do psicanalista. Enfrentá-los, contornando o risco de rebaixar o campo do inconsciente - campo da fala e da linguagem - à comunicação intersubjetiva, nos exige avançar a pesquisa psicanalítica.

Precisamos compreender melhor como se estruturam esses novos sintomas pois, freqüentemente, não sabemos dizer se são neuroses ou psicoses ou, até, se são novas neuroses e novas psicoses. Em conseqüência das mudanças na civilização, precisamos retomar os princípios da teoria e da prática psicanalítica para expandir as modalidades de tratamento, para subsidiar a psicanálise aplicada com fins terapêuticos em instituições de saúde, escolares e jurídicas. É preciso incentivar a pesquisa universitária sobre os princípios da prática psicanalítica, os finais de análise e a própria finalidade de uma psicanálise, para que a universidade possa assumir o papel que ela deve ter na formação de psicanalistas e pesquisadores em teoria psicanalítica. 
Em resposta a essas perguntas começamos por tomar como método fazer do vício virtude (Coelho dos Santos, mar.2004, p. 63-74). Se a posição subjetiva dominante nos dias de hoje é a reivindicação de ser tratado como uma exceção (Coelho dos Santos e Azeredo, dez.2005, p. 77-96; Coelho dos Santos e Freitas, set.2005, p. 246-60) e se o lugar do Outro na contemporaneidade oscila entre a impotência e a impossibilidade, a clínica psicanalítica hoje deve partir do caso a caso. É a conseqüência da precariedade dos universais, quando o simbólico é mais inconsistente e mais fragmentado, e não temos mais certeza de que o complexo de Édipo seja o sintoma coletivo. Não é suficiente classificar o sujeito como neurótico ou psicótico, de acordo com a presença ou a ausência do Nomedo-Pai. Muitas vezes, um ponto de vista continuista, baseado na quantidade pulsional, aponta que alguns sintomas neuróticos podem ser tão graves quanto outros tantos sintomas psicóticos. Na história do movimento psicanalítico, alguns desses pacientes foram classificados como borderlines e tratados por meio da contratransferência como recurso técnico.

O surgimento de uma teoria da técnica baseada na contratransferência foi o índice de que alguns analistas, e Wilhelm Reich em particular, já percebiam que a distinção entre neurose e psicose não era muitas vezes tão nítida. Foi o sinal de que os poderes da interpretação do inconsciente, como um retorno do recalcado, eram insuficientes diante das novas modalidades de sofrimento psíquico. O desejo do analista, conceito lacaniano, não é - ao contrário do que se costuma repetir - sem relações com a contratransferência. Mais além do inconsciente - que é estruturado como a linguagem - há um real da pulsão que é sem lei, em jogo na relação analítica. O desejo do analista, conceito lacaniano, foi fundamental para acolher a potência crítica, mas também superar a técnica de contratransferência (Coelho dos Santos, mar.2004, p. 68-71). Avançamos a nossa pesquisa em direção ao mais além do Édipo e do inconsciente, abordando o real sem lei da pulsão, por meio da inexistência da relação sexual. O desacordo entre o saber e o gozo enraíza-se na diferença sexual e na dissimetria dos gozos feminino e masculino.

\section{Uma nova abordagem dos limites da interpretação}

Para tratar os novos sintomas, que muitas vezes parecem inclassificáveis - nem neuróticos, nem psicóticos - é preciso que a investigação psicanalítica não reduza o Nome-do-Pai ao prisma exclusivo do complexo de Édipo (Coelho dos Santos, 2005, p. 61-92). Em conseqüência da universalização dos direitos do homem e do progresso da ciência, existe uma tendência ideológica muito forte 
e poderosa na contemporaneidade à homogeneização dos sexos e das gerações. Essa ideologia, que nasceu com os movimentos sociais pela igualdade entre os sexos e as gerações produziu - quando de seu nascimento, nas décadas de 1960 e 1970, e o faz mais ativamente hoje - o desbussolamento do homem contemporâneo assim como a confusão de referências identificatórias.

O significante mestre, base da identificação, vacila, apaga-se ou é rebaixado. O índice mais evidente dessa nova configuração de valores é a quase inexistência de homens excepcionais. No lugar dos grandes inventores, escritores, governantes, políticos e visionários, a cena pública exibe hoje, sem pudor, uma grande quantidade de personagens medíocres, de cultura de massa, de governantes impotentes, de políticos corruptos, de homens míopes e manipuladores (Miller, 2003). Dificilmente continuaremos a pensar a função do Nome-do-pai, por meio da força constituinte, da autoridade obscura, poética, infundada do homem excepcional ou do texto sagrado. O declínio desse lugar sagrado e dissimétrico vai de par com o esvaziamento do valor da transmissão da experiência entre as gerações (Coelho dos Santos, 2004, p. 1-32).

Não é apenas o declínio da diferença geracional que afeta o indivíduo contemporâneo de uma tendência à desidentificação. Também a desvalorização da diferença sexual tem efeitos de desregulação do corpo, do prazer e do gozo. $\mathrm{O}$ advento do discurso da ciência, apoiado na assunção de que todos os homens nascem livres e iguais, vem desenvolvendo uma concepção de ciência baseada em evidências estatísticas que impõem várias modalidades de avaliação dos indivíduos de acordo com um padrão, ou um tipo de homem/mulher médio. $\mathrm{O}$ efeito dessa nova mentalidade avaliadora e homogeneizante é o de nos levar a presumir que existe um homem/mulher sem qualidades, o que desembocou na psicopatologia prêt à porter do DSM-IV.

No lugar da fina psicopatologia clássica, herdada da psiquiatria e desenvolvida pela psicanálise, temos uma nova literatura científica que se refere a sintomas que nos parecem ilegíveis, porque nascem com essa forma de recusa do inconsciente e da singularidade do sujeito (Miller, nov.2005-abr.2006). A dúvida quanto ao diagnóstico é uma constante na prática atual. Como as psicoses são hoje muito menos delirantes, e podem ser estabilizadas por meio de psicoterapias e medicamentos, muitas vezes não se distinguem das novas formas da neurose. Também as neuroses são muito menos alimentadas pelo sentido. No lugar da renúncia à sexualidade, verificamos uma tendência muito acentuada em direção a modalidades substitutas de satisfação: compulsões, adições, pânico, depressões que dispensam o sentido, pois se referem a um objeto determinado. No lugar das grandes doenças do Outro consistente - neuroses, psicoses e perversões - temos muito mais doenças da mentalidade. Estas últimas se distinguem por uma precariedade simbólica que alguns pesquisadores em 
psicanálise acreditam ter relação com a fraqueza da metáfora paterna, mas que se manifestam como uma subjetividade carente de autonomia e responsabilidade (Coelho dos Santos, set.2005, p. 74-81).

Como Jacques Lacan havia formulado no conhecido artigo "A ciência e a verdade" (1965/1966, p. 855-878), cabe à psicanálise reintroduzir na consideração científica o Nome-do-Pai. O declínio de toda autoridade simbólica na cultura recomenda que no lugar de buscar a função do Nome-do-Pai sob a forma do ideal, do indivíduo excepcional, nos inclinemos, preferencialmente, para os efeitos do complexo de castração, da diferença sexual e da dissimetria essencial entre a modalidade de gozo feminino e masculino. Desse modo, fui levada a reduzir a questão da função paterna ao seu núcleo mínimo: um homem que coloca uma mulher no lugar de objeto-causa do seu desejo. Deixei de procurar sua autoridade obscura e infundada nos emblemas e brasões do pai idealizado. Essa estrutura mínima, o desejo do homem por uma mulher, será ela suficiente para sustentar o fardo pesado da autoridade paterna na constituição do sujeito, e separar meninos e meninas de suas mães?

\section{A clínica do real}

Partir de um mínimo estrutural, em tempos de desprezo pela estrutura, exige ir além da alternativa entre presença e ausência do Nome-do-Pai, como critérios distintivos da neurose e da psicose, para tratar os casos inclassificáveis da clínica contemporânea. Seguindo a orientação sugerida pelos investigadores do Campo Freudiano, sob a coordenação de Jacques-Alain Miller (cf. Miller et al., 1997), estudei a possibilidade de estruturar uma abordagem diagnóstica baseada no critério da quantidade pulsional. Uma clínica continuista, baseada no real da pulsão, em acréscimo à clínica estrutural clássica, baseada no Nome-do-Pai e no inconsciente (Miller et al., 1999). Ela nos remete mais diretamente àquilo que regula a angústia: o sofrimento psíquico, a invasão de gozo. No curso dessa elaboração fui levada a reconsiderar o papel do complexo de castração na abordagem da questão do sintoma neurótico ou psicótico como modo de regulação ou de desregulação pulsional. Justamente nesse ponto, fui obrigada a reconhecer que, porque o gozo não se reduz ao sentido, o homem e a mulher não podem ser reduzidos ao "sujeito do significante"; nem a particularidade do seu desejo pode ser homogeneizada sob a fórmula do fantasma unissex: $\$<>a$ (Coelho dos Santos, 2005b, p. 37-53). Acredito que na neurose, bem como na psicose, o sintoma que regula o gozo é diferente conforme o sexo (Coelho dos Santos et al., no prelo). 
Comecei a testar a hipótese de que a diferença estrutural entre neurose e psicose não é um critério suficiente para classificar e tratar o sofrimento psíquico. É preciso reintroduzir a diferença entre os modos de regulação do real pulsional de homens e mulheres. A regulação fálica, própria ao sexo masculino, é muito diferente da desregulação erotomaníaca, própria ao gozo feminino. Na psicose, observamos muitas vezes um "empuxo à mulher". Entretanto, o excesso pulsional e a desregulação numa mulher não são necessariamente psicoses. Em tempos de declínio da função paterna é preciso ter em conta a dissimetria dos modos de gozo masculino e feminino. Passei, então, a refazer o percurso do conceito de complexo de castração em Freud (1923, p. 177-86). Destaquei as linhas principais da constituição do sujeito, menino ou menina, diante da diferença sexual (Freud, 1925, p. 303-22). Em particular sua consideração acerca das diferenças entre as atitudes frente ao complexo de castração, bem como a entrada e a saída do Édipo em meninos e meninas. É o temor de ser castrado que leva o menino a sair do Édipo. A menina entra no Édipo em conseqüência do sentimento de injúria narcísica por não ter sido contemplada pela mãe com a posse do pênis (Freud, 1924, p. 215-26).

Retomei, à luz dos seminários de Lacan, a importância distintiva do pai para um e para o outro sexo. Ele é o agente imaginário da castração para o menino, que interdita o objeto incestuoso e se torna um traço na identificação constitutiva do supereu. Para a menina, ele é aquele que tem o pênis e pode dálo, bem como pode dar um filho como seu substituto. Diferentemente do menino, o pai não interdita propriamente o objeto incestuoso, nem se faz um traço de identificação no caso das meninas (Freud, 1931, p. 257-81). Pude renovar o sentido, tantas vezes mal-interpretado, da afirmação freudiana de que as mulheres não têm um supereu "tão inexorável, tão impessoal e tão independente de suas origens emocionais como exigimos que o seja nos homens" (Freud, 1925, p. 319-20). Essa dupla matriz ganha toda sua importância quando se trata de avaliar os resultados de uma análise. $O$ rochedo da castração gira em torno do destino dos restos das relações com o mesmo sexo, que Freud chamou de repúdio da feminilidade. Os homens temem a castração, e por essa razão temem submeterse a um outro homem. As mulheres aferram-se à reivindicação do falo, como defesa contra os resíduos de suas relações libidinais arcaicas com sua mãe (Freud, 1933, p. 139-65). O repúdio da feminilidade, para um e para o outro sexo, a sexuação como homem ou como mulher, é o resto irredutível de uma análise (Freud, 1937, p. 239-87). A psicologia de cada um, seu caráter conforme o seu sexo, é o rochedo da castração. Nesse ponto, a pulsão, na fronteira entre o somático e o psíquico, é um acontecimento provocado pela incorporação do significante a um corpo anatômicamente sexuado. Somente a incorporação do significante, homem ou mulher, permite ao ser humanizado pela linguagem asceder 
à sexualidade psíquica. É sobre esse terreno real da pulsão que as elucubrações fantasmáticas do inconsciente vão se assentar. É preciso, para compreender melhor os transtornos da sexuação, referir-se à diferença entre o real e o inconsciente.

Efetuei um percurso nas formulações lacanianas sobre a diferença entre os sexos (Coelho dos Santos, 2005c, p. 65-117). Verifiquei que no seu esforço de significantização do complexo de Édipo, e na intenção de elevar o mito à dignidade da estrutura, esse psicanalista promoveu, durante alguns anos de sua elaboração, uma teoria da constituição do sujeito relativamente indiferente à diferença sexual. O axioma: "o sujeito é o que um significante representa para um outro significante", que tantas vezes repetimos, não nos exige saber se o sujeito do significante é um homem ou uma mulher. As virtudes econômicas dessa formalização tenderam a reduzir as diferenças imaginárias entre os sexos, em particular as anatômicas, à diferença simbólica entre dois significantes. O que vem a ser um homem ou uma mulher? Quando se trata tão-somente de significantes, parece que o sexo anatômico não é o aspecto mais relevante em jogo, e sim a pura nomeação (Freud, 1937, p. 117-43).

Ao acentuar a distinção entre a pulsão e o instinto, Lacan promoveu a tese de que a pulsão não tem objeto, destacando o valor enigmático do desejo sexual. No fantasma inconsciente, são os objetos parciais que servem às finalidades de satisfação pulsional. Essa ferramenta conceitual ressaltou demasiadamente a idéia de que a sexualidade é autoerótica, e completamente desligada das finalidades naturais da biologia. Essa tendência foi reforçada pela formalização da fantasia inconsciente. A fórmula do fantasma, $\boldsymbol{S}<>$ a, implica que consideremos que todo sujeito é sujeito do significante identificado ao traço paterno ideal e que deseja um objeto parcial, resto do gozo não significantizado (Lacan, 1964). A fórmula é unissex e o objeto do gozo fantasmático é auto-erótico. Como explicar então a orientação de um sexo em direção ao outro? Como é que se chega, uma vez que se parte do fantasma auto-erótico e unissex, ao encontro do parceiro heterossexuado e à cópula? (Freud, 1937, p. 143-65).

As leituras da sexuação, ensejadas pelo seu Seminário XX, Mais, ainda, (Lacan, 1972/1973, p. 73-82) aprofundaram a redução do sexo anatômico às suas conseqüências psíquicas (Coelho dos Santos, maio-out.2006). As fórmulas da sexuação promovem uma teorização do funcionamento psíquico masculino e feminino, como suplências da relação sexual que não há. Elas nos levaram a acreditar que qualquer indivíduo poderia, idealmente, situar-se do lado masculino ou feminino da tábua da sexuação. O que é feito da diferença anatômica entre os sexos? Minha hipótese é a seguinte: pelo fato de na psicose masculina existir freqüentemente um empuxo no sentido de encarnar e fazer existir "A Mulher" absoluta, acreditou-se que essa posição subjetiva comprovaria que o sexo 
anatômico é independente do sexo psíquico. Uma outra evidência abusivamente utilizada em apoio da dissociação entre sexo anatômico e sexo psíquico é o fato de que algumas mulheres histéricas exibem teatralmente uma certa virilidade, resultado de uma identificação com o homem. Ambas as evidências contribuíram para apagar as marcas do exame delicado, que Freud perseguiu, das "conseqüências psíquicas da distinção anatômica entre os sexos".

Recentemente, Jacques-Alain Miller esforçou-se para desenvolver uma tese acerca da biologia em jogo na obra de Lacan. Destacou em particular a idéia de que o sintoma é um acontecimento significante de corpo (Miller, fev.2000, p. 760). Deste modo, acredito que é preciso deslocar a questão da sexuação do campo dos efeitos do complexo de castração, do Édipo e da função paterna, para o campo mais precoce da incidência da língua. Antes mesmo que um ser falante compareça como acontecimento significante de corpo, ele é falado pelo Outro materno. Uma das primeiras marcas que uma criança recebe é a designação rígida como menino ou menina. Por essa razão, entre as marcas precoces desta nomeação primeira funda-se a possibilidade de que alguém reconheça, ou não, "sua anatomia como seu destino."

Em seu artigo, "A partilha sexual", Miller (1999b, p. 7-28) nos apresenta toda uma tipologia do caráter masculino e feminino, bastante subversiva das representações tradicionais dos gêneros. Desenvolve, conforme os efeitos de uma lógica opositiva entre o ter e o não ter, a psicologia essencialmente prudente própria ao masculino. Avança, por outro lado, aquilo que é próprio às mulheres: a posição destemida e a tendência a afrontar todo aquele que pretende ocupar o lugar de exceção. O que explica essa vocação feminina para a confrontação é, como ele nos propõe, o fato de a mulher não ter nada a perder. Quem não tem nada a perder, também não se submete à regulação fálica. Penso que essa tipologia é extremamente útil para compreender a diferença essencial entre os sintomas masculinos e femininos. Ela surge da dissimetria essencial entre o modo de gozo feminino (excesso sem lei) e masculino (lei fálica). O homem, identificado ao pai como exceção (\$), deseja a mulher como objeto a, causa do seu desejo. As mulheres, por sua vez, procuram no homem a conjunção falo/pênis, que lhes proporciona um certo efeito de identificação e de regulação do excesso pulsional. Entretanto, isso não é tudo. Tal como Freud, Lacan reconhece que o continente negro da feminilidade não é o mesmo que a sexualidade feminina. A feminilidade, ele a formaliza por meio do matema $\mathrm{S}(\mathbb{A})$, que designa o gozo feminino como a fala enquanto tal. Do seu parceiro ela espera que ele fale, que ele lhe enderece palavras de amor. O impasse entre os sexos nasce dessa dissimetria entre o gozo sexual feminino e o masculino. O gozo da mulher é tecido no discurso amoroso, enquanto que o homem aborda silenciosamente seu objeto fantasmático (Lacan, 1972/1973, p. 73-82). 
Penso que as conseqüências mais férteis dessa formalização se destacam em seu Seminário inédito RSI (1975/76), quando ele redefine a função paterna reduzindo-a ao seu osso: a escolha que faz um homem de uma mulher como objeto do seu desejo (Coelho dos Santos, 2006, p. 57-72). Uma mulher precisa consentir em fazer às vezes desse objeto causa do desejo. No seminário seguinte, intitulado "Le Sinthome" (Lacan, 1975/1976, p. 101), ele desenvolve uma nova ética, a da responsabilidade sexual. Uma mulher é, para um homem, um sinthoma. Um homem é, para uma mulher, pior que um sintoma, uma aflição.

\section{Do Nome-do-Pai ao real sem lei: sexuação e invenção}

Com base nessa breve revisão das minhas principais considerações teóricas atuais, situo algumas questões a serem mais profundamente investigadas. Acredito que essa pesquisa sobre os fundamentos da psicopatologia psicanalítica contribua para atualizar os "princípios da direção da cura psicanalítica", retomando-os a partir dos impasses da sexuação. Isso é importante para orientar os praticantes da psicanálise aplicada sobre o que podemos esperar (sem abrir mão dos princípios dessa prática) no âmbito dos efeitos terapêuticos. Acredito que essa discussão contribua para renovar a controvérsia sobre a diferença entre a neurose e a psicose na contemporaneidade.

A antiga grafia da palavra sintoma - sinthoma - vem aqui designar o que ele tem de mais essencial, seu osso. É em torno dessa diferença de grafia que vou desenvolver as novas etapas da minha pesquisa. Os sintomas de um sujeito masculino são os resíduos das fixações auto-eróticas e o índice da não dissolução do complexo de Édipo. O sinthoma é outra coisa. Como Lacan precisou, uma mulher é, para um homem, um sinthoma (Lacan, 2005, p. 101). Uma mulher é o sinthoma de um homem, eu interpreto assim, porque ela localiza para ele o excesso da pulsão de morte. Uma mulher encarna, para um homem, o real sem lei da pulsão. Quero investigar mais detidamente as raízes da posição sexuada masculina em suas relações com o Nome-do-Pai. Em particular, trata-se de averiguar o laço entre a identificação (S1) e as modalidades de escolha da parceira, com base no objeto $a$. Dada a estrutura normal do desejo fetichista masculino, como se traça a via que leva à paternidade para cada um? É preciso renovar a distinção entre a posição sexuada masculina da neurose obsessiva, uma vez que a tradição lacaniana muitas vezes tende a reduzir uma a outra.

Freud distinguia a sexualidade feminina (Weiblich sexualität) e a feminilidade (Weiblichkeit). Distinguir os sintomas femininos, do sinthoma masculino. Haverá 
do lado da mulher um sinthoma? Segundo Lacan, “... um homem é para uma mulher pior que um sintoma, uma aflição" (Lacan, 1975/1976, p. 101). Pelo estudo dos relatos de final de análise (Coelho dos Santos, 2006, p. 57-72), venho tentando desdobrar as modalidades do consentimento feminino à posição de objeto do desejo de um homem (Coelho dos Santos, nov.2006). Como uma mulher se acomoda no fantasma masculino? Em que medida essa acomodação ao fantasma de um homem, é reveladora do famoso continente negro da feminilidade, ou das obscuras relações primitivas de uma menina com sua mãe? Será que um homem sempre precisa fazer um certo cálculo sobre as relações de uma mulher com sua mãe, para levá-la a consentir em encarnar o que, para ele, é um objeto $a$ ? (Laurent, maio-out.2006). Por outro lado, uma mulher precisa, segundo Lacan, localizar no corpo do homem o significante do seu desejo (Lacan, 1958, p. 685696). Isso é suficiente para localizar o real sem lei do gozo feminino? Existe conjunção ou disjunção entre a relação de uma mulher a $S(\mathbb{A})$ - o discurso amoroso - e ao falo? Como distinguir os efeitos terapêuticos de um final de análise propriamente dito quanto a esse ponto?

A palavra sinthoma é utilizada, no Seminário XXIII, com outro sentido ainda, quando Lacan se refere aos efeitos de uma análise. A hipótese do inconsciente, ele esclarece, não é nada mais que o efeito da crença em Deus, no Nome-doPai. Ela é correlativa da suposição de saber ao Real. Ainda de acordo com Lacan nesse mesmo seminário, podemos "prescindir do Nome-do-Pai, à condição de sabermos nos servir dele" (Lacan, 1975/1976, p. 136). Como exemplo desse ultrapassamento, ele apresenta a invenção do Real, isto é, seu próprio sinthoma. O Real é o nome que Lacan inventa para o campo da pulsão de morte, afastandose, por meio da invenção de uma nova escrita borromeana da pulsão, da energética freudiana. O que significa, entretanto, esse outro uso da palavra sinthoma, que designaria um passo no sentido de prescindir, sabendo se servir do Nome-doPai? (Coelho dos Santos, 2005d). Será que a invenção de uma escrita é sempre o caminho masculino para se separar da submissão a um outro homem? É o modo masculino de tratar o repúdio da feminilidade? Será que Lacan nos oferece, por meio de seu próprio caso, ao final da análise, a invenção como um ultrapassamento da ameaça de castração?

Finalmente, Lacan define o analista como um sinthoma. Como se articulam então, ao final da análise, a sexuação e a invenção para homens e mulheres? Deveríamos designar pelo artigo definido, o psicanalista e a psicanalista? Que lições podemos retirar desse esforço lacaniano de circunscrever e nomear a pulsão de morte e o incurável no final das análises para repensar as estruturas, as construções e o tratamento possível da psicose? 
Referências

Coelho dos Santos, Tânia. Quem precisa de análise hoje? São Paulo: Bertrand Brasil, 2001.

. Le sacré dans la modernité, dans la gauche e dans la pratique lacanienne. Lettre mensuelle de l'École de la Cause Freudienne, Paris, v. 223, p. 1-32, 2004.

. O que não tem remédio, remediado está! Revista Latinoamericana de Psicopatologia Fundamental, São Paulo, v. VII, n. 1, p. 63-74, mar.2004.

. A prática lacaniana na civilização sem bússola. In: SANTos, Tânia Coelho dos (org.). Efeitos terapêuticos na psicanálise aplicada. Rio de Janeiro: Contracapa, 2005a. p. 61-92. 37-53, $2005 b$.

. O sinthoma e a insígnia: fantasia ou caráter? Latusa, Rio de Janeiro, n. 10, p.

Sinthoma: corpo e laço social. Rio de Janeiro: Sephora/UFRJ, 2005c.

. Por l'ex-sistencia de un significante nuevo! Acheronta, Argentina, n. 21, jul.2005. Disponível em $<$ http://www.acheronta.org.ar $>$

. A psicopatologia psicanalítica em Freud à Lacan. Pulsional Revista de Psicanálise, São Paulo, ano 18, n. 183, p. 74-81, set.2005.

. O psicanalista é um sinthoma. Latusa, Rio de Janeiro, n. 11, p. 57-72, 2006.

. A redução do sexo anatômico às suas conseqüências psíquicas. Editorial de aSEPHallus, revista do Núcleo Sephora de Pesquisa, ano 1, n. 2, maio-out.2006. Disponível em: www.nucleosephora.com/asephallus.

. Não se pode amar e ser feliz ao mesmo tempo? In: XII EnCONTRO Do CAMPo FreUDIANO, nov.2006, Belo Horizonte. Anais... Belo Horizonte, 2006.

Coelho dos Santos, Tânia; Freitas, Rachel Amin. A escuta analítica no espaço público. Mal-estar e subjetividade, Fortaleza, v. V, n. 2, p. 246-260, jun.2005.

Coelno dos Santos, Tânia; Azeredo, Fábio Moraes de. Um tipo excepcional de caráter. Psyché - Revista de Psicanálise, São Paulo, ano IX, v. V, p. 77-96, dez.2005.

Coelho dos Santos, Tânia et al. Se todo gordo é feliz, a obesidade é um sintoma ou uma solução? In: BAstos, Angélica (Org.). Interseções da psicanálise. Rio de Janeiro: Contracapa (no prelo).

Freud, Sigmund (1923). A organização genital da libido. In: Edição Standard Brasileira das Obras Psicológicas Completas. Rio de Janeiro: Imago, 1977. v. XIX, p. 177-186.

. (1924). A dissolução do complexo de Édipo. In: Edição Standard Brasileira das

Obras Psicológicas Completas. Rio de Janeiro: Imago, 1977. v. XIX, p. 215-226. 
. (1925). As conseqüências psíquicas da distinção anatômica entre os sexos. In: Edição Standard Brasileira das Obras Psicológicas Completas. Rio de Janeiro: Imago, 1977. v. XIX, p. 303-322.

. (1931). Sexualidade feminina. In: Edição Standard Brasileira das Obras Psicológicas Completas. Rio de Janeiro: Imago, 1977. v. XXI, p. 257-281.

. (1933). Feminilidade. In: Edição Standard Brasileira das Obras Psicológicas Completas. Rio de Janeiro: Imago, 1977. v. XXII, p. 130-165

. (1937). A análise terminável e interminável. In: Edição Standard Brasileira das Obras Psicológicas Completas. Rio de Janeiro: Imago, 1977. v. XXIII, p. 239-287.

LaCAN, Jacques (1955/1956). Le seminaire. Livre III. Les Psychoses. Paris: Seuil, 1981.

. (1958). La signification du phallus. In: Écrits. Paris: Seuil, 1966.

. (1962/1963). Le seminaire. Livre X. L'Angoisse. Paris: Seuil, 2004.

. (1964). Le seminaire. Livre XI. Les quatre concepts fondamentaux de la psychanalyse. Paris: Seuil, 1973.

. (1965/1966). La science et la verité. In: Écrits. Paris: Seuil, 1966.

. Écrits. Paris: Seuil, 1966. . (1968-1969). Le seminaire. Livre XVI. D'un Autre à l'autre. Paris: Seuil, 2006. . (1969/1970). Le seminaire. Livre XVII. L'envers de la psychanalyse. Paris: Seuil, 1991. . (1972/1973). Le seminaire. Livre XX. Encore. Paris: Seuil, 1975. . (1974/1975). Seminário XXII. (Inédito).

. Autres Écrits. Paris: Seuil, 2001.

. (1975/1976). Le seminaire. Livre XXIII. Le Sinthome. Paris: Seuil, 2005.

LAURENT, D. O sujeito e seus parceiros libidinais: do fantasma ao sintoma. aSEPHallus, Revista do Núcleo Sephora, Rio de Janeiro, ano 1, n. 2, maio-out.2006. Disponível em: www.nucleosephora.com/asephallus. Acesso em 12 dez. 2006.

Miller, Jacques-Alain. Los signos del goce. Barcelona: Paidós, 1999a. . Un répartitoire sexuel. La Cause freudienne, Paris, n. 40, p. 7-28, $1999 \mathrm{~b}$. 32, Oct.1999. . Les six paradigmes de la jouissance. La Cause Freudienne, Paris, n. 43, p. 7. Biologie lacanienne et événement de corps. La Cause freudienne, Paris, n. 47, p. 7-60, Fév.2000. $\overline{\operatorname{Mars} 2001 .}$

. Quand les semblants vacillent. La Cause Freudienne, Paris, n. 47, p. 7-18, 
. Psychanalyse pure, psychanalyse appliquée et pyschothérapie. La Cause Freudienne, Paris, n. 46, p. 7-36, Mai2001.

. Le réel est sans loi. La Cause Freudienne, Paris, n. 49, p. 7-20, Nov.2001.

. L'ex-sistence. La Cause Freudienne, Paris, n. 50, p. 7-25, Fév.2002.

$\overline{\text { Mai2002. }}$

. Le dernier enseignement de Lacan. La Cause Freudienne, Paris, n. 51, p. 7-34, . Le neveu de Lacan. Paris: Verdier, 2003.

. A era do homem sem qualidades. aSEPHallus, ano 1, n. 1, nov.2005 a abr.2006. Disponível em <www.nucleosephora.com/asephallus>. Acesso em: $15 \mathrm{dez} 2006$.

Miller, Jacques-Alain et al. La conversation d'Arcachon: les inclassables de la clinique. Paris: Le Paon, Agalma, Seuil, 1997.

MilLer, Jacques-Alain et al. La psychose ordinaire, la convention d'Antibes. Paris: Le Paon, Agalma, Le Seuil, 1999.

Miller, Jacques-Alain et al. El Outro que no existe y sus comitês de ética. Barcelona: Paidós, 2005.

\section{Resumos}

(Sobre los principios de la psicopatología psicoanalítica: sexuación e invención)

Estimo que esta investigación sobre los fundamentos de la psicopatología psicoanalítica contribuirá para actualizar los principios de la dirección de la cura psicoanalítica, retomándolos a partir de los impases de la sexuación. Esto es importante para orientar a los practicantes del psicoanálisis aplicado sobre aquello que se puede esperar - sin que se tenga que abrir mano de los principios de ésta práctica - en el ámbito de los efectos terapéuticos. Pienso que esta discusión será un aporte para renovar la controversia sobre la diferencia entre neurosis y psicosis en los días de hoy.

Palabras clave: Psicopatología psicoanalítica, pulsiones, sexuación, invención

(Sur les principes de la psychopathologie psychanalytique: sexuation et invention)

Le but de la présente recherche sur les fondements de la psychopathologie psychanalytique est de contribuer à la mise à jour des principes de la direction de la guérison psychanalytique à partir des impasses de la sexuation. Ceci joue un rôle important dans l'orientation des pratiquants de la psychanalyse appliquée par rapport à ce qu'on peut attendre dans le domaine des effets thérapeutiques, sans renoncer aux

Rev. Latinoam. Psicopat. Fund., São Paulo, v. 11, n. 1, p. 55-68, março 2008 
principes de cette pratique. Nous sommes convaincus que cette discussion va contribuer au renouvellement du débat sur la différence des structures névrotiques et psychotiques dans la contemporanéité.

Mots clés: Psychopathologie psychanalytique, pulsions, sexuation, invention

(On the principles of psychoanalytic psychopathology: sexuation and invention)

It is hoped that this study based on psychoanalytic psychopathology will be useful in updating some of the principles of psychoanalytical treatment by relating them to impasses in sexuation. This is an important factor in orienting practitioners of psychoanalysis regarding the therapeutic effects that can be expected, without their having to abandon their principals. It is hoped that this discussion will contribute to the debate on the structural differences between neurosis and psychosis.

Key words: Psychoanalytical psychopathology, drives, sexuality, invention

Versão inicial recebida em fevereiro de 2007

Versão aprovada para publicação em outubro de 2007

\section{Tania Coelho dos Santos}

Professora Associada do Programa de Pós-Graduação em Teoria Psicanalítica do Instituto de Psicologia da Universidade Federal do Rio de Janeiro - PUC-RJ (Rio de Janeiro, RJ, Brasil); doutora em Psicologia Clínica pela Pontifícia Universidade Católica do Rio de Janeiro - PUCRJ; Pós-Doc no Départmant de Psychanalyse da Universidade Paris-VIII, França; membro da Associação Universitária de Pesquisa em Psicopatologia Fundamental (São Paulo, SP, Brasil); membro da Escola Brasileira de Psicanálise (Rio de Janeiro, RJ, Brasil) e da Associação Mundial de Psicanálise (Buenos Aires, Argentina).

Rua Prof. Julio Lohman, 430 - Joatinga

22611-170 Rio de Janeiro, RJ, Brasil

Fonefax: (21) 493-6306

e-mail: taniacs@openlink.com.br 